\title{
A confocal microwave imaging implementation for breast cancer detection
}

\author{
Nirmine Hammouch, Hassan Ammor \\ Research Team in Smart Communications, Engineering for Smart and Sustainable Systems Research Center, \\ Mohammed V University in Rabat, Morocco
}

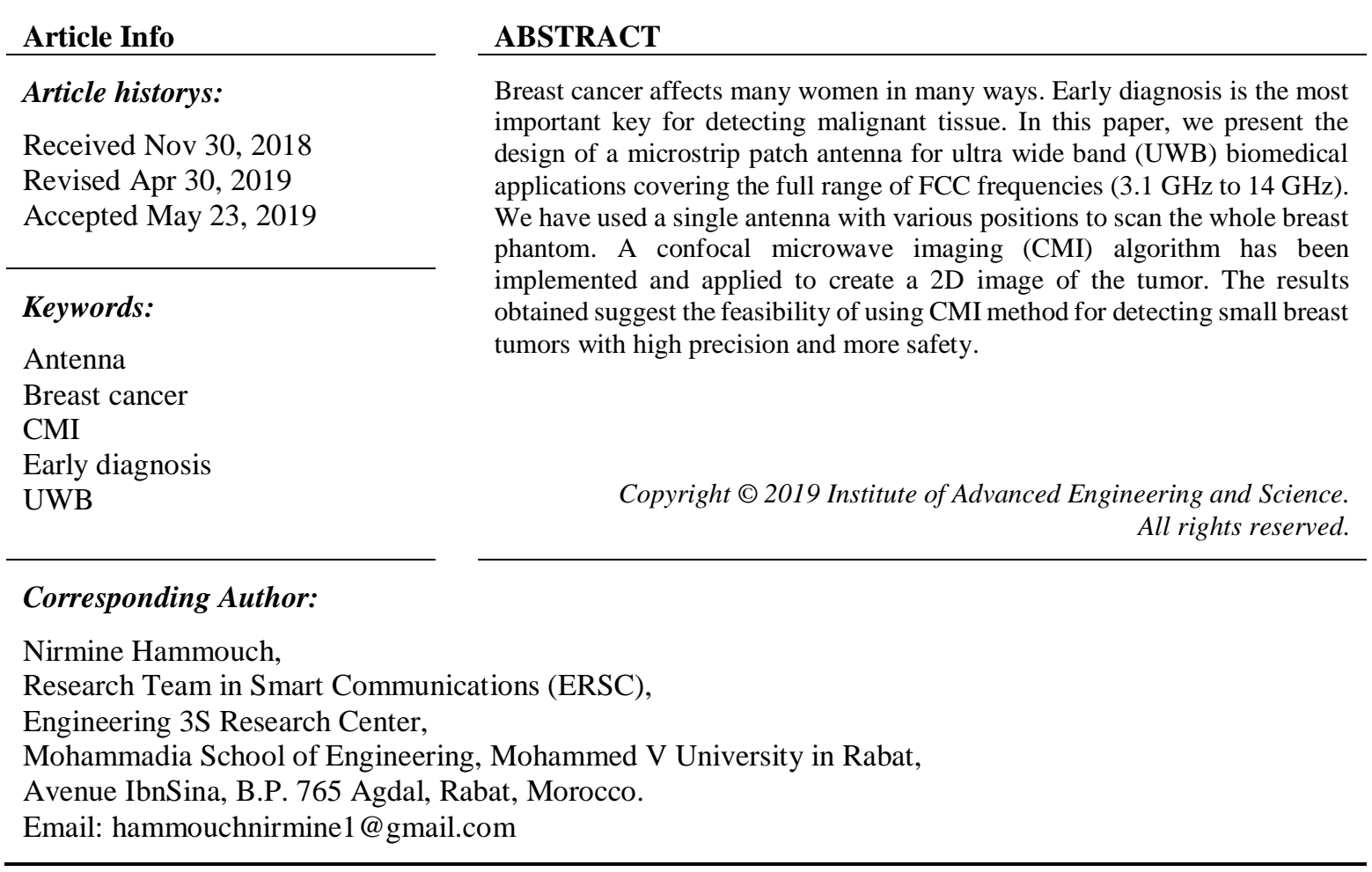

\section{INTRODUCTION}

Breast cancer is an anxiety for many women. Early diagnosis is the most important key for a fast and effective treatment before the increase of this disease in the whole body. Currently, the X-ray Mammography is the most technique used for breast cancer screening. While this technique offers clear advantages, it also generates a wide range of limitations and potential risks such as false positive and false negative results, painful breast compression and ionizing radiation. For that reason, many research teams are looking now for ways more safety and efficiency [1-4]. Microwave imaging is the golden diagnostic tool for medical imaging modality developed over the past few years. This technique offers many interesting advantages for breast cancer like low cost, non-invasive, more safety, and high accuracy [5-10]. Confocal Microwave Imaging (CMI) has been proposed as a method to detect tumors by analyzing the scattered signals from the breast. CMI algorithm is based on image reconstruction using multiple signals collected from ultra wide band (UWB) antenna placed at different positions received from the surface of the breast [11-15].

In this paper, we present an image reconstruction algorithm, namely Confocal Microwave Imaging (CMI). In our work, we present an UWB antenna with a wide frequency band according to the Federal Communications Commissions (FCC) standard. A 3D breast model has been prepared which is approximate replica of human breast. In the following section, we will explain the implementation of Confocal Microwave Imaging (CMI) Algorithm by moving a single antenna around the breast to reconstruct images with simulated data. 


\section{BREAST MODEL}

The design of the proposed breast model for this study is shown in Figure 1. It contains different layers such as skin, fatty tissue.... Each layer has different dielectric characteristics that based on different equations developed in [16, 17]. Figure 2 and 3 show the Gabriel model of different breast layers.

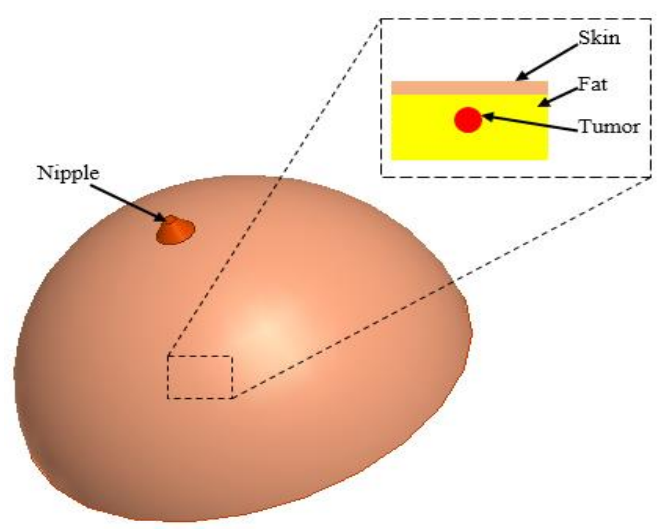

Figure 1. Breast model [8]

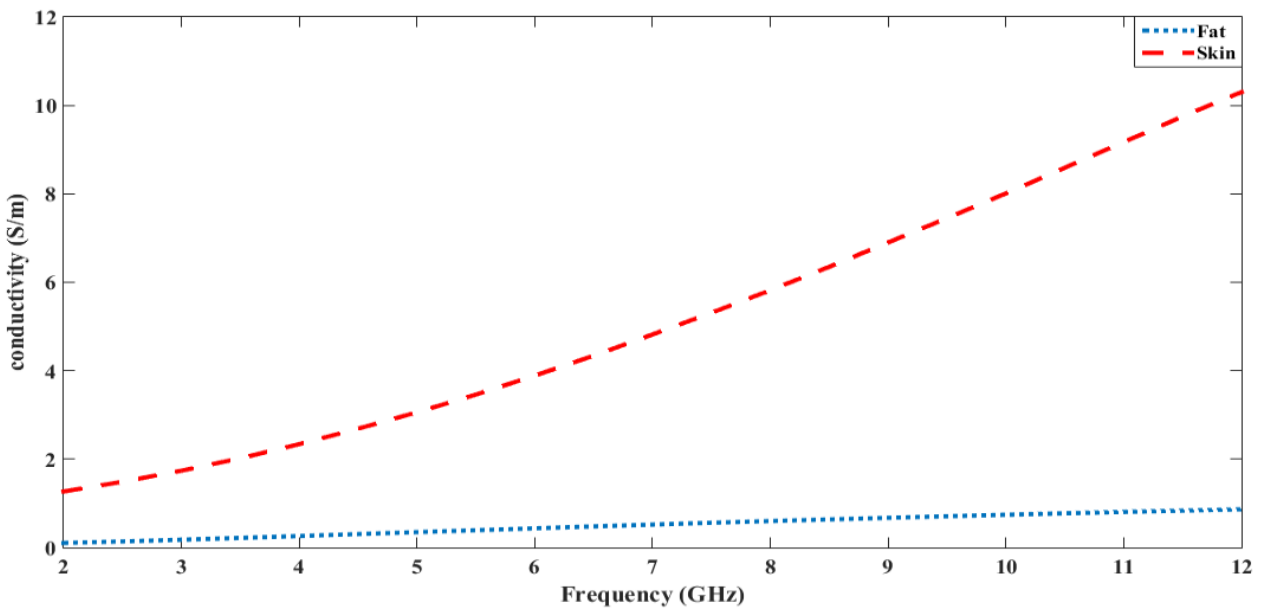

Figure 2. Conductivity of different breast layers [8]

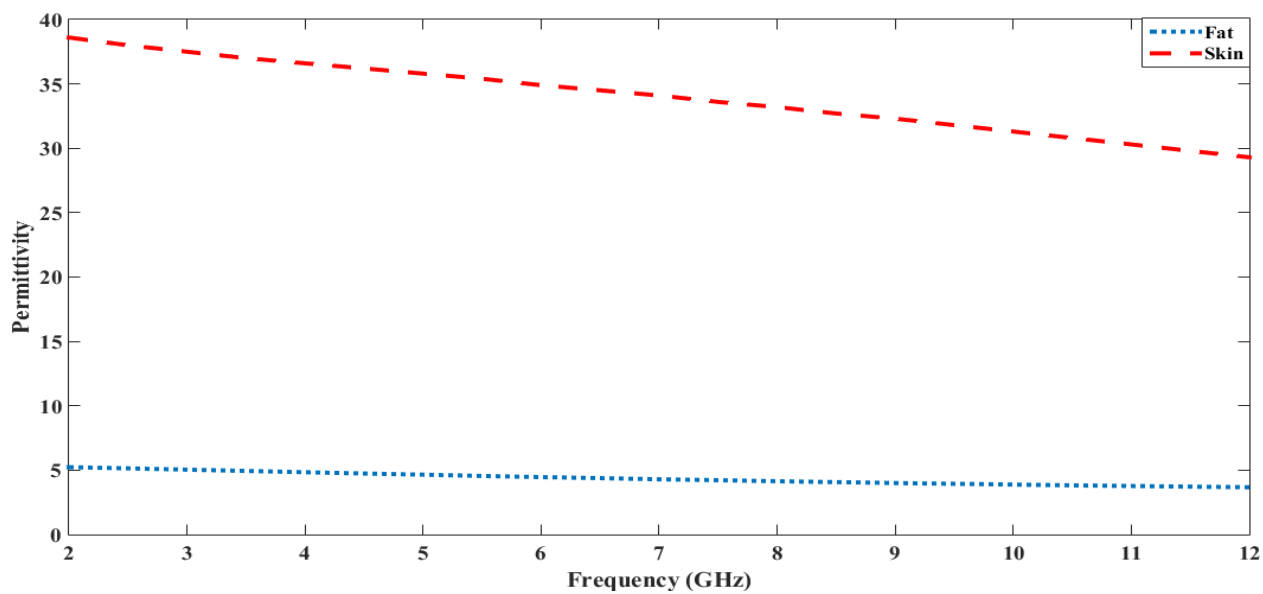

Figure 3. Permittivity of different breast layers [8] 


\section{ANTENNA MODEL}

Figure 4 illustrates the schematic of the proposed UWB antenna. The antenna with a size of Ws $x$ Ls is implemented on FR4 substrate with relative permittivity $\varepsilon r=4.3$, loss tangent of $\delta=0.02$ and thickness of $\mathrm{t}=1.58 \mathrm{~mm}$, the final dimensions of the antenna structure and all techniques applied to improve the performances of the proposed antenna are introduced in $[17,18]$. Optimal dimension as shown in Table 1.

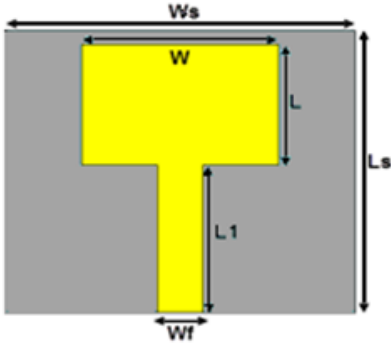

(a)

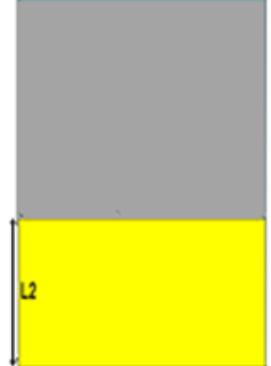

(b)

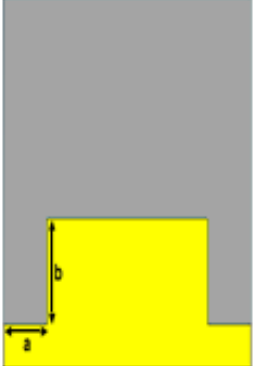

(c)

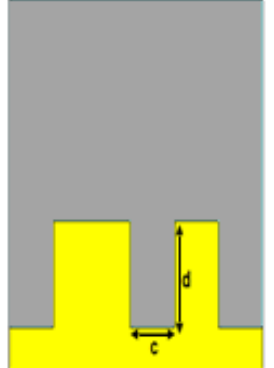

(d)

Figure 4. (a), Geometry of the proposed antenna (b), (c), (d), Design evolution of the final ground plane

Table 1. Optimal dimensions

\begin{tabular}{cccc}
\hline Parameters & Value $(\mathrm{mm})$ & Parameters & Value $(\mathrm{mm})$ \\
\hline Ls & 21 & Wf & 3 \\
Ws & 23 & t & 1.58 \\
L & 9 & a & 4 \\
W & 13 & b & 6.5 \\
L1 & 11 & c & 4 \\
L2 & 8.5 & d & 6 \\
\hline
\end{tabular}

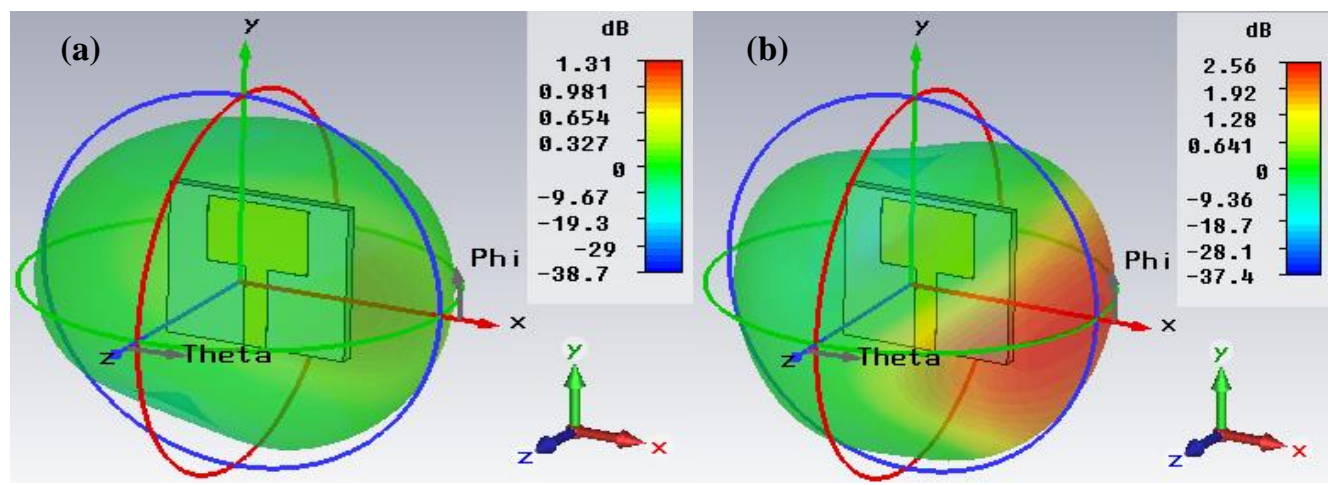

Figure 5. Radiation pattern 3D of the basic antenna at (a) : $3.65 \mathrm{GHz}$ and (b) : $8.64 \mathrm{GHz}$

Farfield Gain Theta (Phi=90)

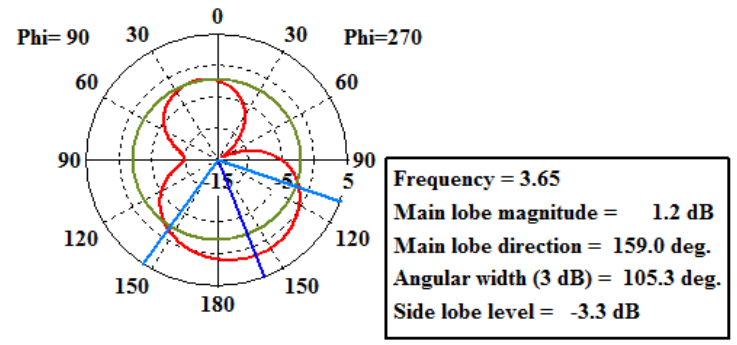

Theta / Degree vs. dB
Farfield Gain Phi $(\mathrm{Phi}=0)$

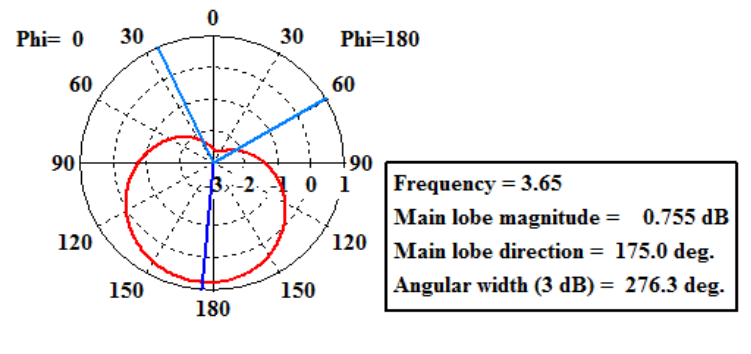

Theta / Degree vs. dB

Figure 6. Radiation pattern 2D of the basic antenna at $3.65 \mathrm{GHz}$ 
Farfield Gain Theta $(\mathbf{P h i}=90)$

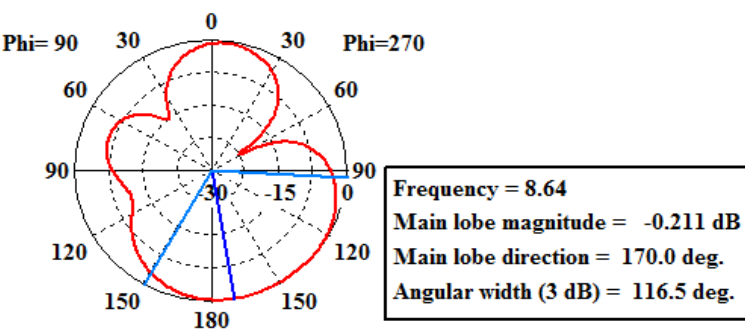

Theta / Degree vs. dB

\section{Farfield Gain Phi $(\mathbf{P h i}=0)$}

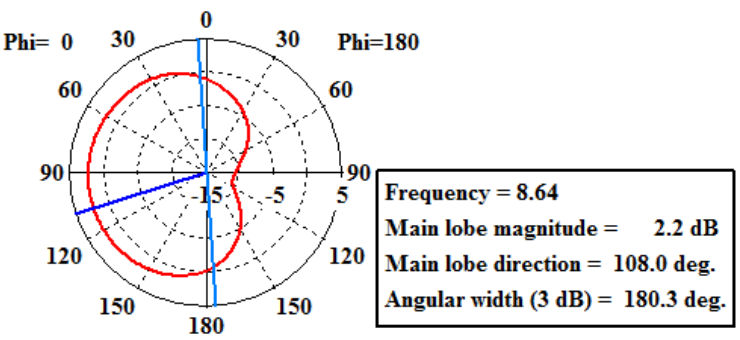

Theta / Degree vs. dB

Figure 7. Radiation pattern 2D of the basic antenna at $8.64 \mathrm{GHz}$

Radiation patterns of the proposed antenna is approximately omnidirectional, as shown in Figure 5-7. It is observed that the antenna has good radiation characteristics for all resonance frequencies. The photograph of fabricated UWB antenna prototype is shown in Figure 8.

The comparison between the $\mathrm{S}$ parameter measured with two different electromagnetic solvers is shown in Figure 9. A good agreement is found between the simulations in the whole band, but we remark some differences due to the fact that they are based on two different meshing techniques and solving algorithms (FIT, FEM). Even with the small difference in the $S$ parameter, the results confirm that, the bandwidth of the antenna is from 3.1 to $14 \mathrm{GHz}$, which covers the full range of FCC frequencies from 3.1 to $10.6 \mathrm{GHz}$.
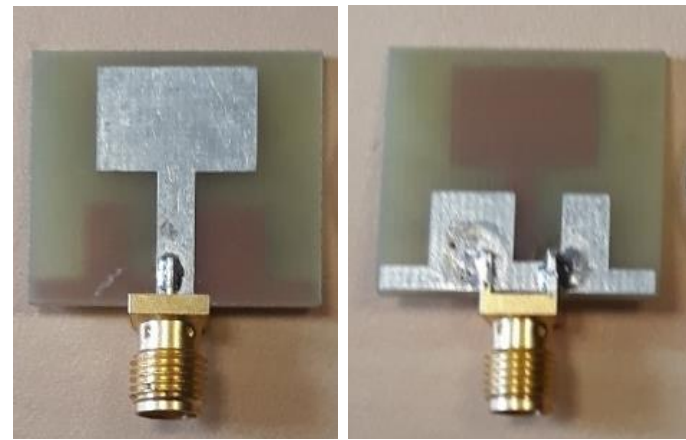

Figure 8 . The photograph of fabricated UWB antenna prototype

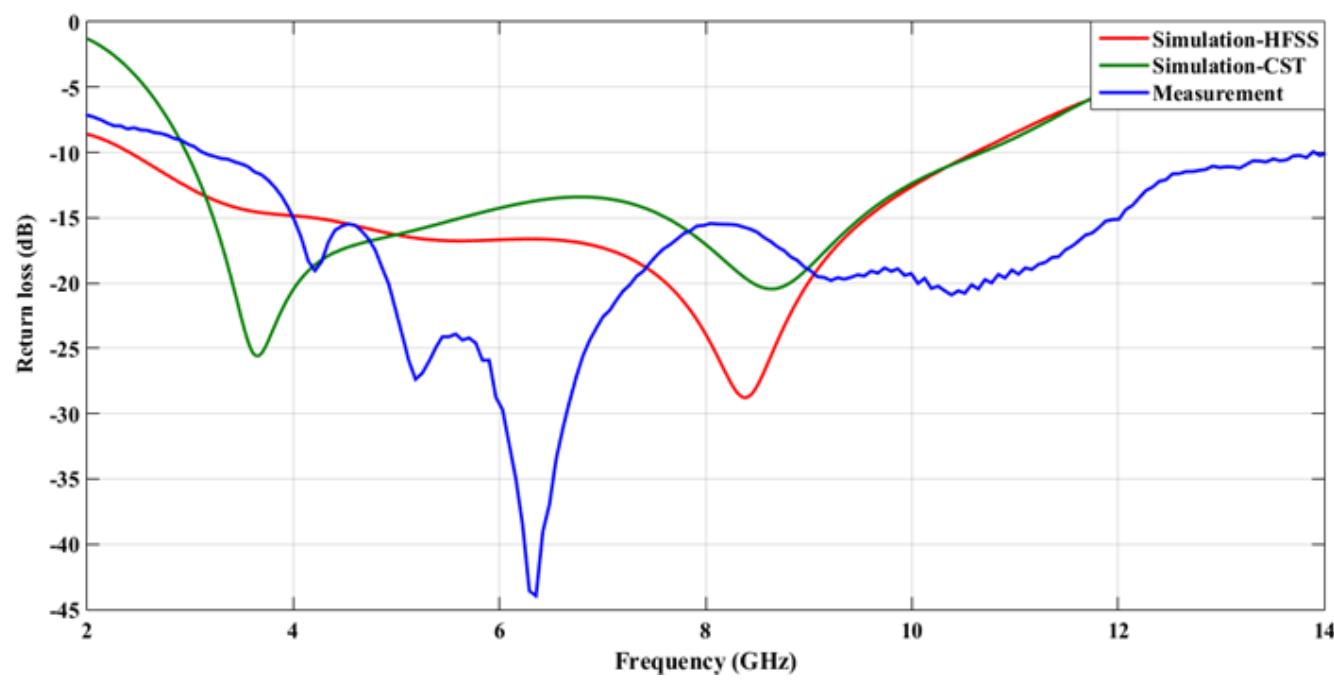

Figure 9. Simulated and measured $\mathrm{S}_{11}$ for the proposed antenna 
A good agreement is found between simulation and measurement results. The proposed antenna has a good performance in the whole band ranging from 3.1 to $14 \mathrm{GHz}$, as noted in Table 2 .

\begin{tabular}{cccc}
\multicolumn{4}{c}{ Table 2. Comparison of previous designs with the proposed antenna } \\
\hline Antenna & Substrat $(\mathrm{Er})$ & $\begin{array}{c}\text { Antenna Area } \\
(\mathrm{mm})\end{array}$ & $\begin{array}{c}\text { Bandwidth }(\mathrm{GHz}) \\
(<-10 \mathrm{~dB})\end{array}$ \\
\hline$[19]$ & & $73.4 \times 41.9$ & $5-10$ \\
{$[20]$} & 4.3 & $45 \times 40$ & $6-10$ \\
{$[21]$} & Not reported & $42 \times 19$ & $3-8$ \\
This work & 3.38 & $21 \times 23$ & $2.96-10.68$ \\
\hline
\end{tabular}

\section{THE CONFOCAL MICROWAVE IMAGING ALGORITHM}

The objective of our breast imaging system is to detect tumors at their early stage and ensure a fast and effective treatment in order to reduce women mortality. In this part, we present our algorithm of the confocal microwave imaging (CMI) introduced in [22], [23]. The frequency domain data is obtained with a monostatic radar, which consists of an UWB antenna used for transmitting and receiving signals. The goal of this technique is to place our antenna at different X-Y positions and transmits microwaves over a wide band of frequencies to give us more accuracy and precision for a complete reconstruction of the image, as illustrated in Figure 10. The positions are distributed in a grid of 121 points (11x11), covering the size of the whole model.
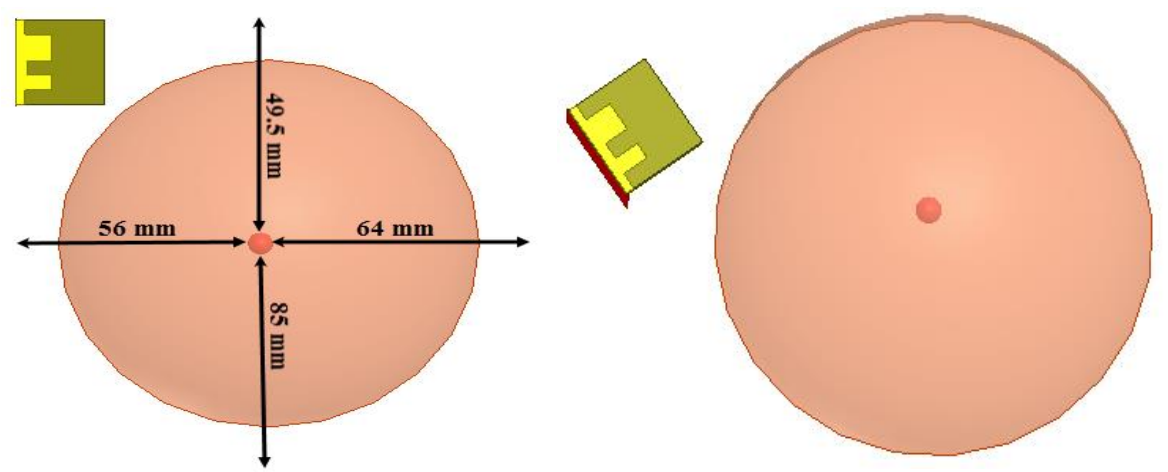

Figure 10. Antenna positions covered the whole model

In this part, we will explain the implementation of CMI algorithm. Five steps were applied to create an image of the tumor.

- Hamming Window: A Hamming window is applied to the signals (with and without tumor) to reduce the level of side lobes $(\mathrm{H}$ : Hamming window, SH: environment without tumor, STH: environment with tumor).

$$
\begin{aligned}
& S H_{X Y}(f)=S_{X Y}(f) * H \\
& S T H_{X Y}(f)=S T_{X Y}(f) * H
\end{aligned}
$$

- Inverse Fast Fourier Transform: The obtained signals were transformed into the time domain by taking the Inverse Fast Fourier Transform (IFFT), as shown in Figure 11-12 for environment with and without tumor, respectively.

$$
\begin{aligned}
& S H_{X Y}(f) \underset{I F F T}{\Longrightarrow} S H_{X Y}(t) \\
& S T H_{X Y}(f) \underset{I F F T}{\Longrightarrow} S T H_{X Y}(t)
\end{aligned}
$$




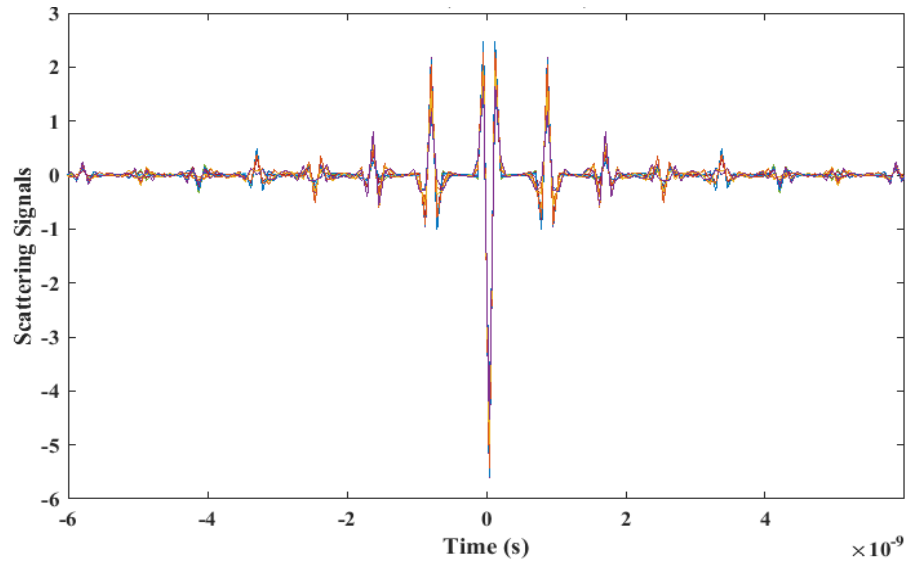

Figure 11. IFFT for the environment with tumor

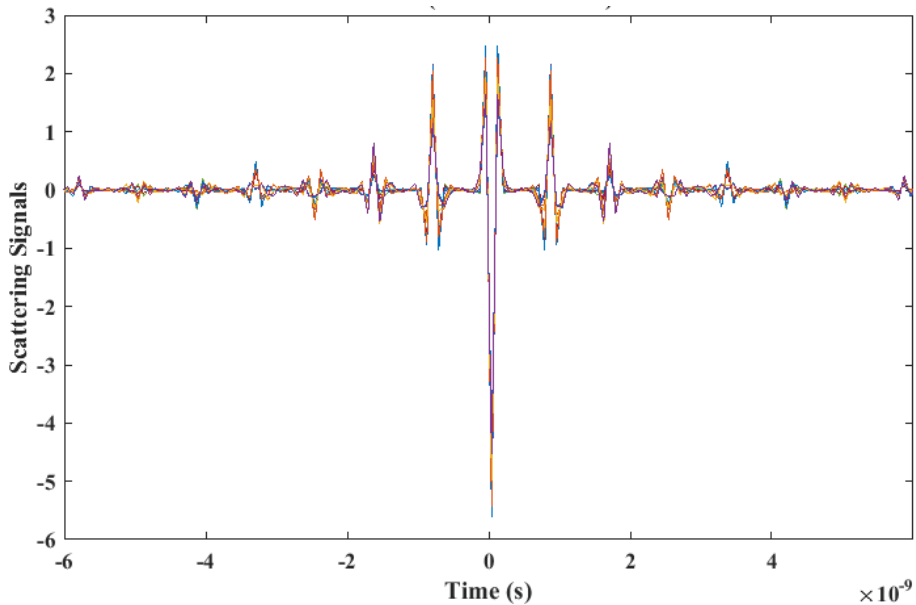

Figure 12. IFFT for the environment without tumor

- Calibration: This technique was used to remove the environment signals and keep only the reflections of the tumor. We subtract the signals SHXY(t) (environment without tumor) from the signals STHXY(t) (environment with tumor), as shown in Figure 13:

$$
S_{X Y}(t)=S T H_{X Y}(t)-S H_{X Y}(t)
$$

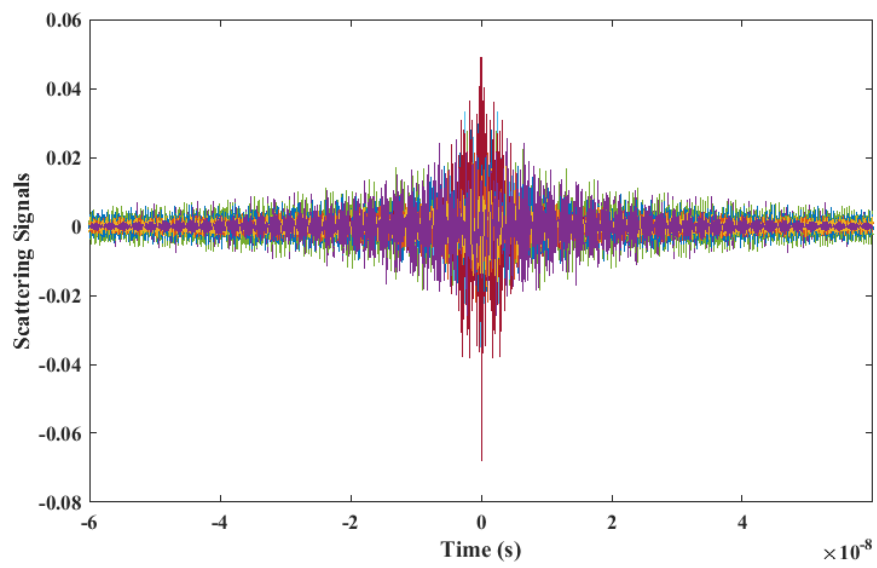

Figure 13. Calibration between two environments 
- Clutter Removal: The obtained signals always contain a mixture of noises due to antenna and environment. This noise is removed by subtracting the averaged signals from each received signal:

$$
\begin{aligned}
& E M(t)=\frac{\sum_{Y=1}^{N} S_{X Y}(t)}{N} \\
& E_{X Y}(t)=S_{X Y}(t)-E M(t)
\end{aligned}
$$

where $\mathrm{N}$ represents the number of rows and columns of the grid of 121 positions of the antenna. The result is shown in Figure 14.

- Generate Pixel points: In this section, we evaluate the distance of each antenna position XY to each pixel covering an area of $(118 \mathrm{~mm} \times 126 \mathrm{~mm})$ in order to calculate the round-trip time. After calculating the time values, The final image is generated by different intensity values for all antenna positions XY (Figure 15).

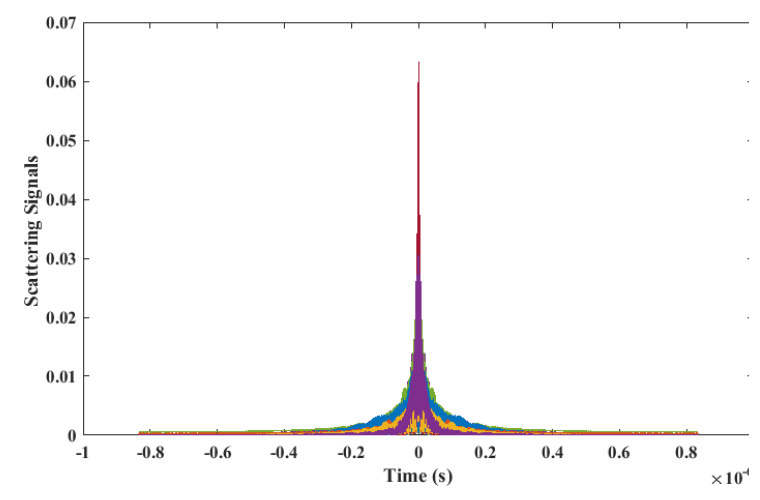

Figure 14. Clutter Removal

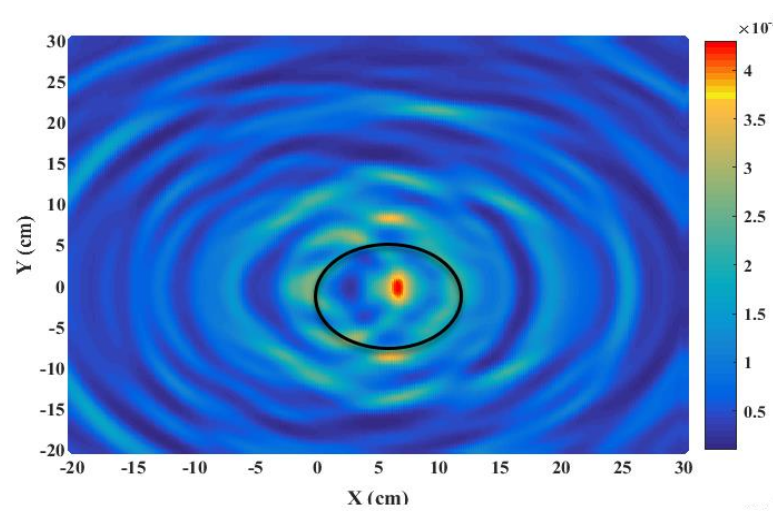

Figure 15. Image result of CMI algorithm

The imaging results are shown in two dimensions by using a single antenna moving around the breast. It is shown that the normal and malignant tissue are easily differentiated. The tumor have very different dielectric properties (high conductivity and relative permittivity), which makes it possible to be detected by analyzing the scattered signals.

The image reconstructed demonstrates the feasibility of using confocal microwave imaging (CMI) algorithm from a monostatic UWB radar system for breast cancer detection.

\section{CONCLUSION}

The results presented in this paper show that it is feasible to detect and localize breast tumors in two dimensions. We proved the validity of our confocal microwave imaging (CMI) algorithm for breast cancer detection. For the first step, An UWB microstrip antenna is designed and fabricated for UWB applications especially for biomedical applications. The measured results show that the antenna can cover a bandwidth ranging from $3.1 \mathrm{GHz}$ to $14 \mathrm{GHz}$ (according to FCC). As a next step, we placed our antenna at different $\mathrm{X}-\mathrm{Y}$ positions, and we applied the CMI algorithm proposed to create a 2D image of the tumor. This technique is able to detect tumors breast with many advantages such as low cost, non-invasive radiation compared to the worldwide screening systems.

\section{ACKNOWLEDGEMENTS}

We thank the members of the laboratory ( $+\mathrm{D}+\mathrm{i}$ of Telecommunications) in the engineering department of communication, University of Cantabria in Spain for their cooperation. 


\section{REFERENCES}

[1] M. Hady Bah, J. S. Hong, D. Ali Jamro, "UWB patch antenna and a breast mimicking phantom are designed and implemented for microwave breast cancer detection using Time Reversal MUSIC,"Microwave and Optical Technology Letters, Vol. 58, No. 3, 2016.

[2] M. Hady Bah, J. S. Hong, D. Ali Jamro, "Ground Slotted Monopole Antenna Design for Microwave Breast Cancer Detection Based on Time Reversal MUSIC," Progress In Electromagnetics Research C, Vol. 59, 117-126, 2015.

[3] R. R. Hasan, R.T. H Tusher, S. Howlader, S. Jahan, "On body e-shaped patch antenna for biomedical application," Indonesian Journal of Electrical Engineering and Informatics (IJEEI), Vol. 7, No. 1, pp. 152-157,2019.

[4] I. Amdaouch, O. Aghzout, A. Naghar, A. V. Alejos, and F. Falcone, "Breast Tumor Detection System Based on a Compact UWB Antenna Design," Progress In Electromagnetics Research M , Vo 1. 64, 123 - 133, 2018.

[5] M. Klemm, J.A. Leendertz, D. Gibbins, I.J. Craddock, A. Preece, and R. Benjamin, "Microwave Radar-Based Differential Breast Cancer Imaging: Imaging in Homogeneous Breast Phantomsand Low Contrast Scenarios," IEEE Transactions on Antennas and Propagation, Vol. 58, No. 7, 2010.

[6] Elise C. Fear, Ph.D, "Microwave Imaging of the Breast," Technology in Cancer Research \& Treatment, vol 4, no 1, 2005.

[7] Md. Z. Mahmud, M. T. Islam, N. Misran, A. F. Almutairi and M. Cho, "Ultra Wideband (UWB) Antenna Sensor Based Microwave Breast Imaging: A Review," Sensors, 18, 2951, 2018.

[8] M. Jalilvand, X uyang Li, L. Zwirello and T. Zwick, "Ultra wideband compact near-field imaging system for breast cancer detection," IET Microw. Antennas Propag, Vol. 9, Iss. 10, pp. 1009 -1014, 2015.

[9] J. Ali, N. Abdullah, R. Yahya, E. Mohd, A. Joret and N. Katiran, "Bistatic configurational analysis of ultra-wideband antenna for detection applications," Indonesian Journal of Electrical Engineering and Computer Science, Vol. 13, No. 2, pp. 702-707, 2019.

[10] N. Ojaroudi, M. Ojaroudi, and Y. Ebazadeh, "UWB/Omni-Directional Microstrip Monopole Antenna for Microwave Imaging Applications," Progress In Electromagnetics Research C, Vol. 47, 139-146, 2014.

[11] Xu Li, and Susan C. Hagness, "A Confocal Microwave Imaging Algorithm for Breast Cancer Detection," IEEE microwave and wireless components letters, Vol. 11, No. 3, 2001.

[12] Elise C. Fear, Xu Li , Susan C. Hagness, Maria A. Stuchly, "Confocal Microwave Imaging for Breast Cancer Detection: Localization of Tumors in Three Dimensions," IEEE transactions on biomedical engineering, VOL. 49, No. 8, 2002.

[13] M. Samsuzzaman and M. T. Islam, "A semicircular shaped super wide band patch antenna with high bandwidth dimension ratio," Microwave and Optical Technology letters, Vol. 57, No. 2, 2015.

[14] A. D. Farhood, M. K. Naji, S. H. Rhaif and A. H. Ali, "Design and analysis of dual band integrated hexagonal shaped microstrip UWB antenna," Indonesian Journal of Electrical Engineering and Computer Science, Vol. 15, No. 1, pp. 294 299,2019.

[15] S. Elajoumi, A. Tajmouati, J. Zbitou, A. Errkik, A. M. Sanchez and M. Latrach, "Bandwidth enhancement of compact microstrip rectangular antennas for UWB applications," Telkomnika, Vol.1 7, No.3, pp.1559-1568, 2019.

[16] C. Gabriel, S. Gabriely and E. Corthout, "The dielectric properties of biological tissues: I. Literature survey," $P$ hys. Med. Biol. 41, 2231-2249, 1996.

[17] N. Hammouch, H. Ammor, "Smart UWB antenna for early breast cancer detection," ARPN Journal of Engineering and Applied Sciences, Vol 13, Issue 11, Pages 3803-3808, 2018.

[18] N. Hammouch, H. Ammor, "An accurate UWB technique for breast cancer detection using microwave specific absorption rate," International Journal of Microwave and Optical Technology, Vol 13, Issue 5, Pages 424-431, 2018.

[19] H. Zhang, A.O. El-Rayis, N. Haridas, N.H. Noordin, A.T. Erdogan and T. Arslan, "A Smart Antenna Array for Brain Cancer Detection," Loughborough Antennas \& Propagation Conference, Loughborough, UK, 14-15 November 2011.

[20] H. Gupta, V. Maheshwari and V.V. Thakery, "Brain Tumor Detection by Microwave Imaging using Planner Antenna," International Journal of Bio-Science and Bio-Technology, Vol.8, No.5, pp. 201-210, 2016.

[21] M.A. Matin, B.S. Sharif and C.C. Tsimenidis, "Microstrip patch antenna with matching slots for UWB communications," Int. J. Electron. Commun-AE, 61, 132-134, 2007.

[22] Sidi mohammed C, Lotfi M, Sidi mohammed M, "A Microwave Imaging Technique Implementation for Early Detection of Breast Tumors," Advances in Circuits, Systems, Signal Processing and Telecommunications (CSST), Dubai, United Arab Emirates, 2015.

[23] Hooi Been L, Nguyen Thi Tuyet N, Er-Ping L, Nguyen Duc T, "Confocal Microwave Imaging for Breast Cancer Detection: Delay-Multiply-and-Sum Image Reconstruction Algorithm," IEEE transactions on biomedical engineering, Vol. 55, No. 6, 2008. 